Check for updates

Cite this: Mater. Adv., 2021, 2, 3336

Received 11th December 2020,

DOI: 10.1039/d0ma00974a

rsc.li/materials-advances Accepted 31st March 2021

\section{An electrochemically exfoliated graphene/poly(3,4-ethylenedioxythiophene) nanocomposite-based electrochemical sensor for the detection of nicotine $\dagger$}

\author{
Jerome Rajendran, ${ }^{a}$ Anatoly N. Reshetilov ${ }^{\mathrm{b}}$ and Ashok K. Sundramoorthy (D) *a
}

\begin{abstract}
A novel, simple and 'green' electrochemical exfoliation method was used to prepare a graphene (GR) dispersion. The as-obtained GR was characterized using HR-TEM, which confirmed the exfoliation of a few layers of graphene from graphite sheets. Furthermore, the GR film was coated on a glassy carbon electrode (GCE) surface via drop-casting. Then, electro-polymerization was carried out using the GR-modified electrode in acetonitrile solution (ACN) containing $10 \mu \mathrm{M}$ 3,4-ethylenedioxythiophene (EDOT) and $100 \mathrm{mM}$ lithium perchlorate $\left(\mathrm{LiClO}_{4}\right)$. The electro-polymerized PEDOT (poly(3,4-ethylenedioxythiophene)) on the GR film-modified electrode was analyzed using FE-SEM and Raman spectroscopy, which confirmed the successful incorporation of PEDOT on the GR surface. The electrochemical characterization of PEDOT/GR/ GCE was carried out by electrochemical impedance spectroscopy (EIS) in $0.1 \mathrm{M} \mathrm{KCl}$ containing $5 \mathrm{mM}$ $\left[\mathrm{Fe}(\mathrm{CN})_{6}\right]^{3-14-}$. The electrochemical measurements revealed that our proposed PEDOT/GR film exhibited a high active surface area, redox currents and high charge transfer rate $\left(K_{\mathrm{s}}\right)$. Under optimized conditions, PEDOT/GR/ GCE showed a higher oxidation peak current for nicotine at $+0.91 \mathrm{~V}(\mathrm{vs}$. $\mathrm{Ag} / \mathrm{AgCl})$ in $0.1 \mathrm{M}$ phosphate buffer solution (PBS; $\mathrm{pH}$ 7). Furthermore, PEDOT/GR/GCE responded linearly for nicotine detection from 0.5 to $1000 \mu \mathrm{M}$ with a limit of detection at $47 \mathrm{nM}$. The selectivity and sensitivity of the electrochemical sensor (PEDOT/GR/GCE) were determined in the presence of important interfering molecules. In addition, the stability and reproducibility of the PEDOT/GR/GCE sensor were tested. Finally, the PEDOT/GR-based sensor was successfully applied to detect nicotine in tobacco samples with high accuracy.
\end{abstract}

\section{Introduction}

Nicotine is a toxic metabolite that is present in tobacco leaves, and is a heavily used addictive substance among adults. ${ }^{1-4}$ As stated by the Centers for Disease Control and Prevention (CDC), about half-million Americans die each year due to exposure to secondhand smoke or smoking. ${ }^{5}$ Smokers burn tobacco leaves, which causes many problems, such as heart disease, stroke, cancer, and lung disease, and also negatively affects the human brain. ${ }^{6,7}$ The concentration of nicotine is $\sim 1-3 \%$ in tobacco products, which determines its quality. Therefore, accurate detection of nicotine is important in various samples for toxicology, medicine and tobacco-related research and development. ${ }^{8-10}$ Traditional methods such as gas chromatography-mass

\footnotetext{
${ }^{a}$ Department of Chemistry, SRM Institute of Science and Technology, Kattankulathur-603 203, Tamil Nadu, India.E-mail: ashokkus@srmist.edu.in ${ }^{b}$ G.K. Skryabin Institute of Biochemistry and Physiology of Microorganisms of the Russian Academy of Sciences (IBPM RAS), Subdivision of "Federal Research Center Pushchino Biological Research Center of the Russian Academy of Sciences" (FRC PBRC RAS), Pushchino 142290, Moscow oblast, Russia

$\dagger$ Electronic supplementary information (ESI) available. See DOI: 10.1039/d0ma00974a
}

spectrometry (GC-MS), ${ }^{11}$ high-performance liquid chromatography (HPLC), ${ }^{12,13}$ radioimmunoassays, ${ }^{14}$ electro-chemiluminescence $(\mathrm{ECL})^{15}$ and liquid chromatography-mass spectrometry (LC-MS) ${ }^{3}$ have been used to analyze the concentration of nicotine. Due to the high cost, extensive sample extraction procedures and sample pretreatment requirements, ${ }^{16}$ alternative highly selective electrochemical sensors have been prepared.

Recently, detection of nicotine was demonstrated using carbon paste electrode (CPE) ${ }^{17}$ glassy carbon electrode $(\mathrm{GCE})^{18}$ and pencil graphite electrode (PGE). ${ }^{1}$ To further improve the stability, selectivity and sensitivity of sensors, chemically modified electrodes were reported. ${ }^{19-21}$ Graphene (GR) is a two-dimensional (2D) honeycomb lattice structured carbon-based material with a delocalized electronic network..$^{22-26}$ GR has exhibited high thermal conductivity, optical transparency, mechanical strength, good flexibility, deep ultraviolet emission, high thermal stability, chemical tolerance (for protective coatings), etc. ${ }^{22,27-29}$ GR can be prepared by either bottom-up or top-down methods. ${ }^{30-35}$ Electrochemical exfoliation is a top-down method which can produce high-yield GR nanosheets at low cost. ${ }^{36-39}$ The as-prepared GR can be used to synthesize nanocomposites with metals, metal oxides, ${ }^{40}$ 


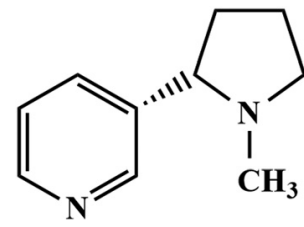

Scheme 1 Chemical structural formula of nicotine.

conducting polymers (CPs) ${ }^{41}$ and some other functional materials to improve sensing performance.

On the other hand, poly(3,4-ethylenedioxythiophene) (PEDOT) is an important $\pi$-conjugated polymer which has been widely used in the fabrication of sensors due to its high stability, conductivity, good biocompatibility, fast electron transfer properties and electro-catalytic activity. ${ }^{42,43}$ PEDOT has also shown anti-fouling properties, which are needed to improve the sensitivity, stability and repeatability of electrochemical sensors. ${ }^{44-46}$ Therefore, the preparation of PEDOT-based nanocomposites could be useful to fabricate electrochemical sensors for nicotine detection with high sensitivity and selectivity. Hybrid films composed of PEDOT and GR have received great attention due to the synergistic effect between the two components. ${ }^{47-49}$ In the present work, electrochemical detection of nicotine was demonstrated using a PEDOT/GR composite-modified electrode.

Firstly, GR was prepared by an electrochemical exfoliation method and characterized by HR-TEM and selected area electron diffraction (SAED) techniques. Secondly, PEDOT was electrochemically deposited onto the GR film-modified electrode. The as-prepared PEDOT/GR hybrid film was characterized by Raman spectroscopy and FE-SEM to investigate the successful deposition and surface morphology analysis. The obtained PEDOT/GR nanocomposite-modified electrode (PEDOT/GR/GCE) showed good electro-catalytic activity and high selectivity towards nicotine. Moreover, the stability and selectivity of the PEDOT/GR hybrid film-modified electrode was tested. The linear response range and limit of detection (LOD) of nicotine were also determined. Finally, the PEDOT/GR/GCE sensor was applied to detect nicotine (Scheme 1) in tobacco samples with high selectivity.

\section{Experimental}

\subsection{Materials and reagents}

Graphite sheets were obtained from Graphite Shop, Inc. (United States). Acetonitrile (AR, ACS), L-ascorbic acid (AR), L-cysteine (CHR), potassium ferrocyanide (AR), potassium ferricyanide (AR) and uric acid (AR) were purchased from Sisco Research Laboratories Pvt. Ltd, India. Dextrose anhydrous, oxalic acid (99.5\%, AR/ACS) and sulfuric acid $\left(\mathrm{H}_{2} \mathrm{SO}_{4}\right)$ were purchased from Loba Chemie, India. Melamine $(99 \%)$ and nicotine $(\geq 99 \%)$ were obtained from Sigma-Aldrich, India. Sodium phosphate dibasic heptahydrate $\left(\mathrm{Na}_{2} \mathrm{HPO}_{4} \cdot 7 \mathrm{H}_{2} \mathrm{O}\right)$ and sodium dihydrogen phosphate monohydrate $\left(\mathrm{H}_{2} \mathrm{NaPO}_{4} \cdot \mathrm{H}_{2} \mathrm{O}\right)$ were purchased from Spectrochem Pvt, Ltd, India. Potassium chloride (KCl) was purchased from Fisher Scientific, India. Hydrogen peroxide was obtained from Merck Life Science Pvt, Ltd, India. The phosphate buffer solution (PBS) (pH 7) was used to prepare the standard $(0.1 \mathrm{M})$ solutions, and the $\mathrm{pH}$ values were adjusted by utilizing different ratios of $\mathrm{NaH}_{2} \mathrm{PO}_{4} \cdot \mathrm{H}_{2} \mathrm{O}$ and $\mathrm{Na}_{2} \mathrm{HPO}_{4} \cdot 7 \mathrm{H}_{2} \mathrm{O}$. Double distilled (Milli-Q) water was used for the preparation of nicotine stock solutions and stored under dark conditions. Milli-Q water $(18.2 \mathrm{M} \Omega \mathrm{cm}$ ) was obtained from a Millipore ultrapure water system. Commercially available cigarettes were purchased from local shops and utilized for real sample preparation and analysis.

\subsection{Characterizations}

The crystal structure and morphology of GR were characterized by a high-resolution transmission electron microscope (HR-TEM) (JEM-2100 Plus Electron Microscope, Japan). A field emission scanning electron microscope (FESEM-EDS) (Quanta 400 FEG, FEI) was used to analyze the microstructures and morphological features of the PEDOT and PEDOT/GR films. All Raman spectra were recorded using the excitation of a $633 \mathrm{~nm}$ laser (LabRAM HR evolution, Horiba, $3.2 \mathrm{~mW}$ laser power source) connected to an Olympus imaging microscope (using Labspec6 Raman software). The calibration of the Raman spectrometer was carried out using a silica standard $\left(520.16 \mathrm{~cm}^{-1}\right)$ before measuring the Raman spectra of each sample with $3.2 \%$ of the maximum laser power $(100 \mathrm{~mW})$. Electrochemical studies such as cyclic voltammetry (CV), electrochemical impedance spectroscopy (EIS) and amperometry were carried out using an electrochemical workstation (CHI$760 \mathrm{E}, \mathrm{CH}$ Instruments, USA). $\mathrm{Ag} / \mathrm{AgCl}(3 \mathrm{M} \mathrm{KCl})$ and platinum wire were used as the reference and counter electrodes, respectively.

\subsection{Preparation of GR}

GR was prepared by an electrochemical exfoliation method. ${ }^{50,51}$ Briefly, graphite sheets $(3 \mathrm{~cm} \times 0.5 \mathrm{~cm})$ were used as electrodes. Graphite sheets $(\sim 1.5 \mathrm{~cm}$ length of both the anode and cathode) were dipped into $50 \mathrm{~mL}$ of $0.1 \mathrm{M}$ PBS (pH 7) for $30 \mathrm{~min}$, and $+10 \mathrm{~V}$ was supplied using a DC power supply (Model: 2231A30-3, Keithley, a Tektronix company, USA). During the electrochemical exfoliation, the partially oxidized graphene nanosheets (GR) were exfoliated and settled in PBS (Fig. S1, ESI†). After the reaction completed, the as-synthesized GR flakes were washed thoroughly using Milli-Q water (through vacuum filtration) to remove the unwanted ions. After that, GR flakes were ultrasonicated in DI water for $60 \mathrm{~min}$ and centrifuged at $3000 \mathrm{rpm}$ to obtain the supernatant GR dispersion. Finally, the GR dispersion (top supernatant solution) was collected and stored for further use.

\subsection{Preparation of the PEDOT/GR-based sensor}

The surface of GCE was cleaned by polishing with a series of alumina particle slurry $\left(\mathrm{Al}_{2} \mathrm{O}_{3}\right.$, particle sizes of $\sim 1 \mu \mathrm{m}, 0.3 \mu \mathrm{m}$ and $0.05 \mu \mathrm{m}$ in sequence) on a polishing pad. Thereafter, GCE was washed with ultrapure Milli-Q water and dried at room temperature. The homogeneous GR suspension $(6 \mu \mathrm{L}$ from $5 \mathrm{mg} \mathrm{mL}{ }^{-1}$ ) was placed on the GCE surface and dried. Next, GR/GCE was rinsed using distilled water to remove the unbound particles. To prepare the PEDOT/GR nanocomposite-modified electrode, EDOT was electro-polymerized on GR/GCE or GR/ITO/ PET (indium tin oxide-coated polyethylene terephthalate) by 
potential cycling between -0.3 and $1.4 \mathrm{~V}$ for 10 cycles at a scan rate of $50 \mathrm{mV} \mathrm{s}^{-1}$ in $10 \mathrm{~mL}$ acetonitrile containing $0.01 \mathrm{M}$ EDOT and $0.1 \mathrm{M} \mathrm{LiClO}_{4}$ (Scheme S1, ESI $\dagger$ ). After the electrochemical polymerization, a dark blue film was observed on the electrode surface, which is the natural color of the PEDOT film (Fig. S2, ESI $\dagger) .{ }^{52,53}$ These results confirmed that PEDOT was successfully deposited on the surface of the GR-modified electrode. The as-prepared PEDOT/GR/GCE was thoroughly rinsed with acetonitrile to remove any loosely bound monomers present on the electrode surface. For the control experiments, PEDOT/GCE (without GR) was also prepared by using a similar procedure.

\subsection{Preparation of tobacco samples}

To prepare the real samples, commercially available cigarettes (10 brands) were purchased from a local departmental shop. First, the filters and rolling papers of these cigarettes were completely removed and the tobacco leaves were collected by mixing and grinding (Fig. S3, ESI $\dagger$ ). After that, $500 \mathrm{mg}$ of tobacco powder was taken in a $25 \mathrm{~mL}$ beaker and mixed with $10 \mathrm{~mL}$ of Milli-Q water. This mixture was ultra-sonicated for 60 min. ${ }^{54}$ Finally, the yellowish solution was filtered through a cellulose nitrate filter paper (pore size $=0.45 \mu \mathrm{m}$ ), and the filtrate was collected and used for further study.

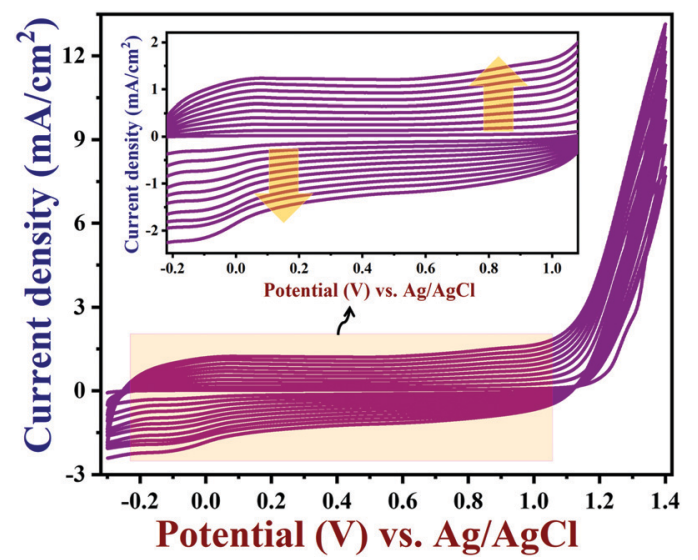

Fig. 1 The electrochemical polymerization of EDOT on GR/GCE from acetonitrile containing $0.01 \mathrm{M}$ EDOT and $0.1 \mathrm{M}$ lithium perchlorate at a scan rate of $0.05 \mathrm{~V} \mathrm{~s}^{-1}$ (10 cycles) (inset: enlarged view).

\section{Results and discussion}

\subsection{Electrochemical polymerization of EDOT on GR/GCE}

Cyclic voltammograms (CVs) were recorded using GR/GCE in the potential window between $-0.3 \mathrm{~V}$ and $+1.4 \mathrm{~V}$ for 10 cycles in acetonitrile containing 0.01 $\mathrm{M}$ EDOT and 0.1 $\mathrm{M} \mathrm{LiClO}_{4}$ (Fig. 1). In this way, PEDOT was deposited on the surface of GR/GCE. The positive potential range was used up to $+1.4 \mathrm{~V}$ for the polymerization in order to avoid any overoxidation on the PEDOT film, which was observed earlier at a higher positive potential. ${ }^{55,56}$ Fig. 1 (inset) shows the uniform deposition of PEDOT on the GR/GCE surface for up to 10 cycles. During the electro-polymerization, the capacitance currents were increased with respect to each cycle, which confirmed the gradual deposition of the PEDOT conducting polymer film on the GR/GCE surface. This was in good agreement with the reported polymerization methods of EDOT in $\mathrm{LiClO}_{4} /$ acetonitrile solution. ${ }^{57}$

\subsection{HR-TEM, FE-SEM and Raman characterizations}

TEM images of the prepared GR are shown in Fig. 2A, which reveals the presence of graphene sheets with a length of $\sim 1.8 \mu \mathrm{m}$. The number of layers in GR was observed by the HR-TEM image analysis (Fig. 2B). As can be seen, a thin GR sheet was observed with few layers, and the interlayer spacing was $0.34 \mathrm{~nm}$, which is in agreement with the lattice distance of graphitic carbon (002). ${ }^{58}$ In addition, the selected area electron diffraction (SAED) patterns of the prepared GR exhibited a six-fold diffraction pattern, which is relevant to the lattice orientation of GR (Fig. 2B, inset). ${ }^{59}$ Furthermore, Fig. 2C shows the TEM images of PEDOT/GR, which confirm the successful deposition of PEDOT on the GR sheets. The surface morphology changes on the electrode surface after deposition of PEDOT and PEDOT/GR were analyzed using FE-SEM. Fig. 3A depicts the surface morphology of the PEDOT, which indicated the formation of a unique $3 \mathrm{D}$ porous network structure. After the coating of GR on the electrode surface, it was found that the GR film uniformly covered the electrode surface (Fig. 3B). Interestingly, after the electro-deposition of PEDOT on the GR-modified electrode, a 3D porous network was clearly observed on the GR surface (Fig. 3C). In addition, PEDOT/GR exhibited the elemental composition of C (38.97\%), O (46.8\%) and $\mathrm{S}(14.23 \%)$ by energy-dispersive X-ray spectroscopy (EDS).

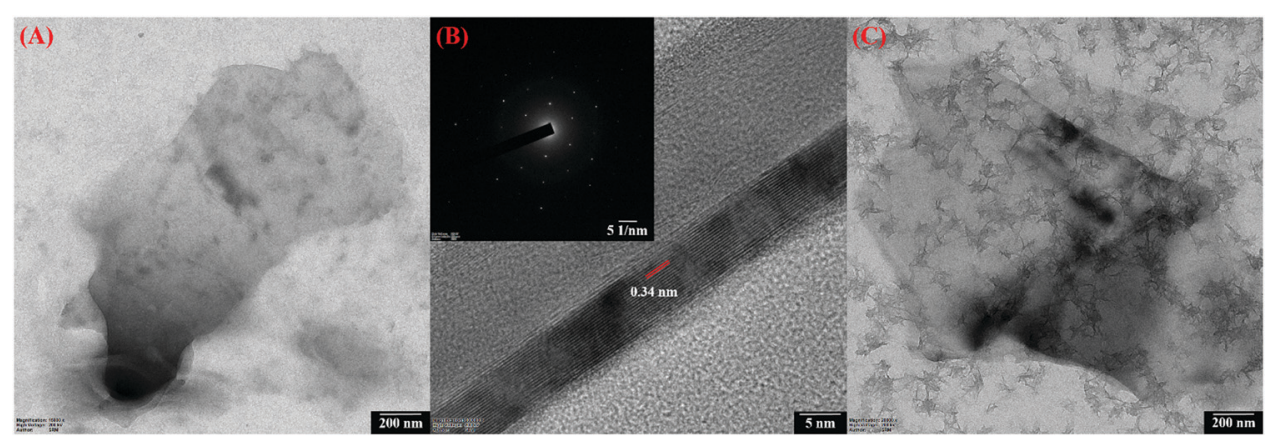

Fig. 2 (A) TEM image of GR and (B) HR-TEM image of GR with corresponding lattice fringes (inset shows the SAED pattern). (C) TEM image of the PEDOT/GR surface. 


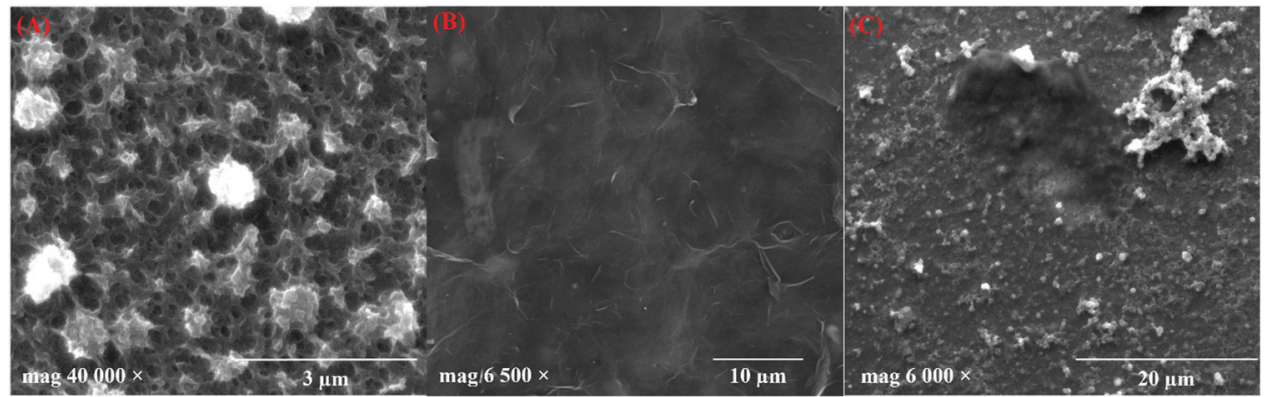

Fig. 3 FE-SEM images of (A) PEDOT, (B) GR film and (C) PEDOT/GR film.

It was confirmed that a hybrid film composed of PEDOT and GR was obtained. The EDS spectra of the GR, PEDOT and PEDOT/GR are provided in Fig. S4 (ESI $\dagger$ ).

Next, the Raman spectrum of GR was recorded (Fig. 4, curve a). The GR exhibited both D and G bands at 1334 and $1581 \mathrm{~cm}^{-1}$, respectively. ${ }^{60}$ Also, the $I_{\mathrm{D}} / I_{\mathrm{G}}$ ratio of the GR was found to be 1.07 , which indicated that GR was partially oxidized. ${ }^{37}$ Furthermore, the Raman spectra of the PEDOT and PEDOT/GR composite were

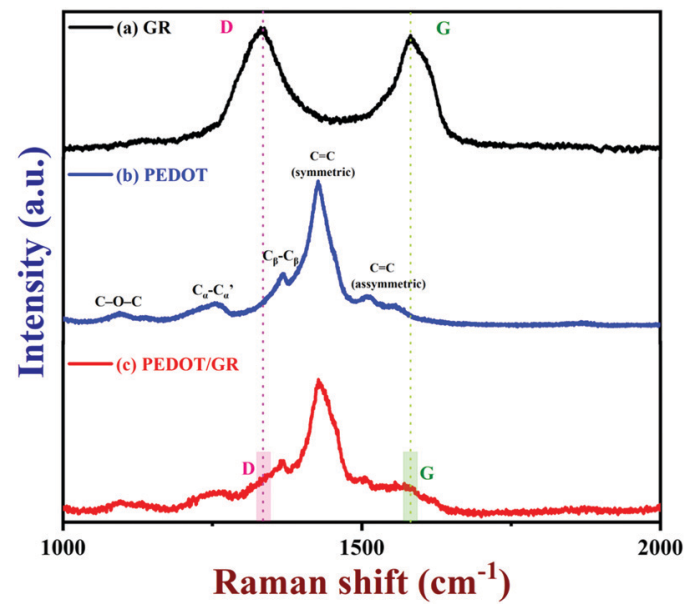

Fig. 4 Raman spectra of (a) GR, (b) PEDOT and (c) PEDOT/GR film (a $633 \mathrm{~nm}$ excitation laser was used). recorded; they showed similar bands corresponding to PEDOT and GR, which confirmed the formation of the PEDOT/GR nanocomposite (Fig. 4, curves b and c). The Raman bands at $1427 \mathrm{~cm}^{-1}$ and $1507 \mathrm{~cm}^{-1}$ indicated the presence of symmetric and asymmetric stretching of $\mathrm{C}=\mathrm{C}$ (curves $\mathrm{b}$ and $\mathrm{c}$ ) ${ }^{61-63} \mathrm{In}$ addition, the other Raman bands observed at 1367, 1259, 1095 and $985 \mathrm{~cm}^{-1}$ denoted the corresponding $\mathrm{C}_{\beta}-\mathrm{C}_{\beta}$ stretching, $\mathrm{C}_{\alpha}-\mathrm{C}_{\alpha}{ }^{\prime}$ inter-ring stretching, $\mathrm{C}-\mathrm{O}-\mathrm{C}$ deformation and oxyethylene ring deformation of PEDOT (curves b and c). ${ }^{64}$ However, it is worth mentioning that the D and G bands of GR were not seen clearly in the Raman spectrum of PEDOT/GR, which was due to the overwhelming Raman bands of the PEDOT film present on GR. However, Raman bands at 1339 and $1585 \mathrm{~cm}^{-1}$ were present in the spectrum of the hybrid film, which indicated that the high-porosity GR sheets were embedded in the PEDOT film (Fig. 4 , curve c). ${ }^{44}$

\subsection{Electrochemical characterization of PEDOT/GR/GCE}

The electrochemical properties of PEDOT/GR/GCE were investigated by EIS and $\mathrm{CV}$ in $0.1 \mathrm{M} \mathrm{KCl}$ containing $5 \mathrm{mM}\left[\mathrm{Fe}(\mathrm{CN})_{6}\right]^{3-/ 4-}$. EIS is one of the most efficient techniques to investigate the interfacial electron transfer resistance $\left(R_{\mathrm{ct}}\right)$ of electrochemical sensors. ${ }^{65}$ The Nyquist plots of bare/GCE, GR/GCE, PEDOT/GCE and PEDOT/GR/GCE were recorded (Fig. 5A). For bare/GCE, GR/GCE and PEDOT/GCE, $R_{\mathrm{ct}}$ values of 70,63 and $50 \Omega$ were obtained, respectively. However, after the deposition of PEDOT
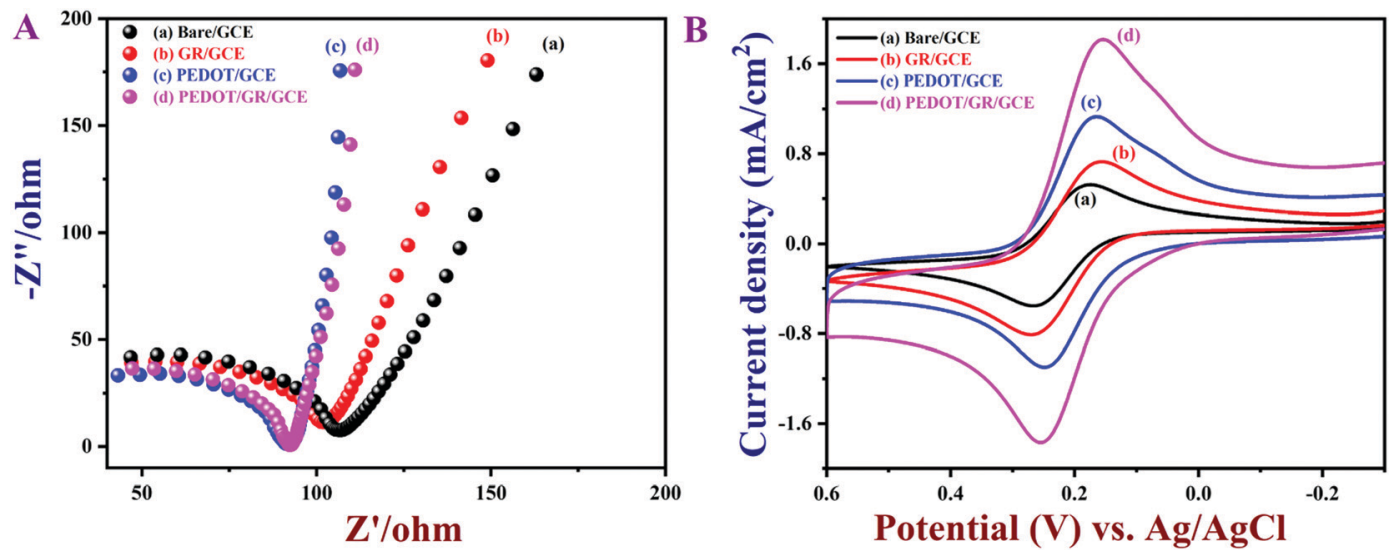

Fig. 5 (A) Nyquist plots and (B) CVs of bare/GCE, GR/GCE, PEDOT/GCE and PEDOT/GR/GCE in $0.1 \mathrm{M} \mathrm{KCl} \mathrm{containing} 5 \mathrm{mM}\left[\mathrm{Fe}(\mathrm{CN})_{6}\right]^{3-/ 4-}$. Scan rate $=0.02 \mathrm{~V} \mathrm{~s}^{-1}$. 
on the GR/GCE surface, the $R_{\mathrm{ct}}$ decreased to $41 \Omega$, which clearly indicated that the PEDOT improved the conductivity of the modified electrode (PEDOT/GR/GCE). In addition, the lowest $R_{\text {ct }}$ value indicated the higher electron transfer efficiency of the electrode. $^{65}$

Fig. 5B shows $\mathrm{CVs}$ of the $\left[\mathrm{Fe}(\mathrm{CN})_{6}\right]^{3-/ 4-}$ on various modified electrodes recorded in $0.1 \mathrm{M} \mathrm{KCl}$ containing $5 \mathrm{mM}\left[\mathrm{Fe}(\mathrm{CN})_{6}\right]^{3-/ 4-}$ at a scan rate of $0.02 \mathrm{~V} \mathrm{~s}^{-1}$. It was obvious that PEDOT/GR/GCE showed a much higher redox peak current $\left(1.81 \mathrm{~mA} \mathrm{~cm}^{-2}\right)$ with a lower peak separation $\left(\Delta E_{\mathrm{p}}\right)$ of $99 \mathrm{mV}$ compared to all the other electrodes, which suggested a quasi-reversible process. ${ }^{66}$ For comparison, $\Delta E_{\mathrm{p}}$ values were calculated from the CVs of $\left[\mathrm{Fe}(\mathrm{CN})_{6}\right]^{3-/ 4-}$ recorded using bare/GCE $(97 \mathrm{mV})$, GR/GCE $(112 \mathrm{mV})$ and PEDOT/GCE $(82 \mathrm{mV})$. These electrodes showed lower redox peak currents compared to PEDOT/GR/GCE, which indicated that the rate of the electron transfer process has been increased due to the synergistic effect between PEDOT and GR. Graphical representations of the different modified electrodes and their $\Delta E_{\mathrm{p}}$ and $R_{\mathrm{ct}}$ values are shown in Fig. S5 (ESI $\dagger$ ).

The electrochemically active surface areas of the modified electrodes were evaluated by $\mathrm{CVs}$ recorded in $0.1 \mathrm{M} \mathrm{KCl}$ containing $\left[\mathrm{Fe}(\mathrm{CN})_{6}\right]^{3-/ 4-}$ at different scan rates from 10 to $100 \mathrm{mV} \mathrm{s}^{-1}$. The CVs of PEDOT/GR/GCE showed a linear response between the redox peak currents and the square roots of the scan rate $\left(\nu^{1 / 2}\right)$ (Fig. S6A and B, ESI $\dagger$ ). Using the Randles-Sevcik eqn (1), the electro-active surface areas $(A)$ of the modified electrodes were calculated. ${ }^{67}$

$$
i_{\mathrm{p}}=2.69 \times 10^{5} \mathrm{~A} \times D^{\frac{1}{2}} n^{\frac{3}{2}} C \nu^{\frac{1}{2}}
$$

where $i_{\mathrm{p}}$ is the peak current $(A)$ and $n$ is the number of electrons involved in the redox reaction. $D, C$ and $A$ have their usual meanings. From the slope value (Fig. S6B, ESI $\dagger$ ), the electro-active surface area of PEDOT/GR/GCE was determined as $0.34 \mathrm{~cm}^{2}$, which was higher than the bare/GCE $\left(0.07 \mathrm{~cm}^{2}\right)$, GR/GCE $\left(0.09 \mathrm{~cm}^{2}\right)$ and PEDOT/GCE $\left(0.22 \mathrm{~cm}^{2}\right)$. Subsequently, the rates of charge transfer $\left(K_{\mathrm{S}}\right)$ of bare/ GCE, GR/GCE, PEDOT/GCE and PEDOT/GR/GCE were calculated using the following eqn (2). ${ }^{68,69}$

$$
R_{\mathrm{ct}}=\frac{R T}{n^{2} F^{2} K_{\mathrm{s}} C}
$$

where $K_{\mathrm{s}}$ is the rate of charge transfer, $n$ is the number of electrons, $C$ is the concentration of $\left[\mathrm{Fe}(\mathrm{CN})_{6}\right]^{3-/ 4-}$ and $T, F$, and $R$ have their usual meanings. The $K_{\mathrm{s}}$ value of PEDOT/GR/GCE was calculated as $1.29 \times 10^{-6} \mathrm{~cm} \mathrm{~s}^{-1}$, which indicated the higher catalytic activity of PEDOT/GR/GCE compared to that of bare/GCE $\left(7.6 \times 10^{-7} \mathrm{~cm} \mathrm{~s}^{-1}\right)$, GR/GCE $\left(8.45 \times 10^{-7} \mathrm{~cm} \mathrm{~s}^{-1}\right)$ and PEDOT/GCE $\left(1.06 \times 10^{-6} \mathrm{~cm} \mathrm{~s}^{-1}\right)$. Finally, it was found that PEDOT/GR/GCE exhibited a higher electroactive surface area, higher current density, lower $\Delta E_{\mathrm{p}}$ and higher charge transfer rate compared to PEDOT/GCE and GR/GCE.

\subsection{Electrochemical oxidation of nicotine}

CVs were recorded to evaluate the electro-catalytic activity of PEDOT/GR-modified GCE in the presence of $100 \mu \mathrm{M}$ nicotine in 0.1 M PBS (pH 7) (Fig. 6, curve a). A highly enhanced oxidation peak was observed at $+0.91 \mathrm{~V}$ for nicotine due to the efficient electro-catalytic oxidation on PEDOT/GR/GCE. At the same

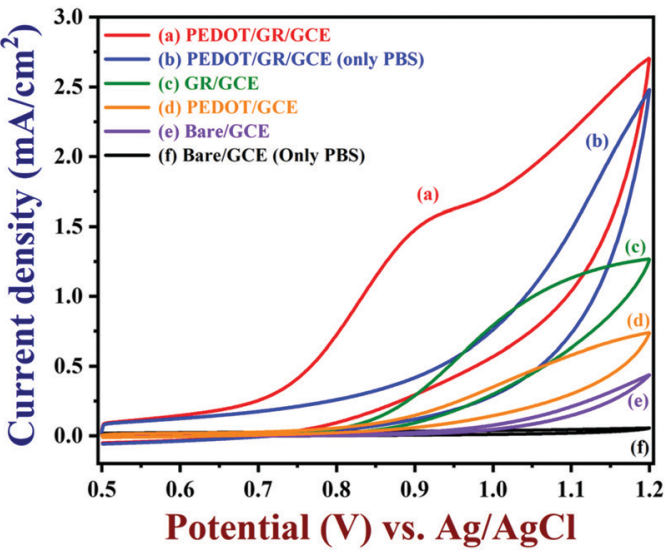

Fig. 6 CVs of PEDOT/GR/GCE (a), GR/GCE (c), PEDOT/GCE (d) and bare/ GCE (e) recorded in $0.1 \mathrm{M}$ PBS $(7 \mathrm{pH})$ with $100 \mu \mathrm{M}$ nicotine. CVs of PEDOT/ GR/GCE (b) and bare/GCE (f) are shown in $0.1 \mathrm{M} \mathrm{PBS}(7 \mathrm{pH})$ without nicotine (scan rate $=0.02 \mathrm{~V} \mathrm{~s}^{-1}$ ).

time, bare/GCE (curve e), PEDOT/GCE (curve d) and GR/GCE (curve c) were utilized to investigate the oxidation of $100 \mu \mathrm{M}$ nicotine at a scan rate of $0.02 \mathrm{~V} \mathrm{~s}^{-1}$ (Fig. 6). In the absence of nicotine, no irreversible oxidation peaks were observed in $0.1 \mathrm{M}$ PBS (Fig. 6, curves $\mathrm{f}$ and $\mathrm{b}$ ) on bare/GCE and PEDOT/GR/GCE. However, after the addition of $100 \mu \mathrm{M}$ nicotine to $0.1 \mathrm{M}$ PBS, bare/GCE showed an oxidation peak at $+1.12 \mathrm{~V}$ (Fig. 6, curve e) with a low peak current of $0.248 \mathrm{~mA} \mathrm{~cm}^{-2}$. This indicated that the bare/GCE required a high voltage for nicotine oxidation. Interestingly, both GR/GCE and PEDOT/GCE showed enhanced nicotine oxidation peak currents at lower potentials of $+1.11 \mathrm{~V}$ and $+1.04 \mathrm{~V}$, respectively (Fig. 6, curves c and d). For comparison, a graph was plotted for the modified electrodes and their respective nicotine oxidation potentials and catalytic currents (Fig. S7, ESI $\dagger$ ). Evidently, the PEDOT/GR-based sensor showed a high oxidation current $\left(1.51 \mathrm{~mA} \mathrm{~cm}^{-2}\right)$ for nicotine at lower potential $(+0.91 \mathrm{~V})$ (Fig. 6, curve a and Fig. S7, ESI $\dagger$ ). This indicated the potential use of PEDOT/GR for the electro-catalytic oxidation of nicotine. The enhanced electro-catalytic activity may arise due to the synergistic effect between the negatively charged GR and positively charged PEDOT.

\subsection{The effect of scan rate on nicotine oxidation}

The effects of different scan rates on the oxidation of $100 \mu \mathrm{M}$ nicotine were studied using PEDOT/GR/GCE in 0.1 M PBS (Fig. 7). The obtained CVs indicated that the nicotine oxidation peak currents linearly increased with the square root of the scan rate from 10 to $100 \mathrm{mV} \mathrm{s}^{-1}$. In addition, the oxidation peak potentials gradually shifted to a high positive potential, which indicated the kinetic limitation of the reaction. ${ }^{70}$ The relationship between the nicotine oxidation current and square root of the scan rate (inset of Fig. 7) displayed a linear equation of $y=0.4675 x-0.4137$ with a correlation coefficient $\left(r^{2}\right)$ of 0.983 . These results suggested that nicotine oxidation on PEDOT/GR/ GCE was a diffusion-controlled process. ${ }^{71,72}$ Next, a graph was plotted between the natural logarithm of the scan rate $(\ln \nu)$ and the oxidation potential $\left(E_{\mathrm{pa}}\right)$ of nicotine, which showed a 


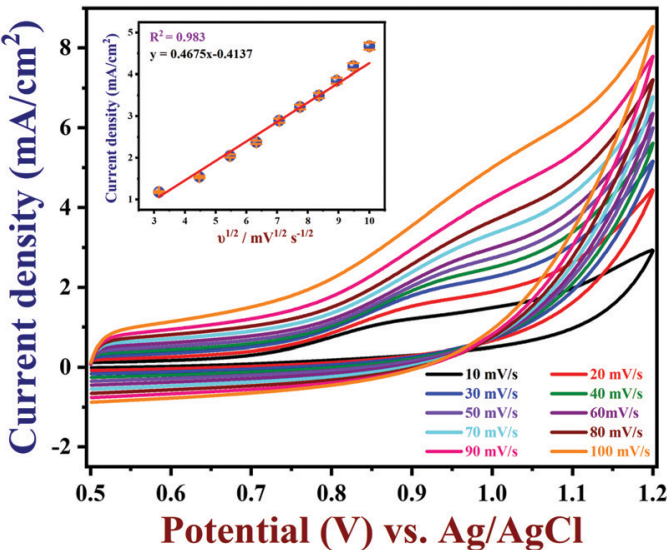

Fig. 7 Effect of scan rate on $100 \mu \mathrm{M}$ nicotine oxidation on PEDOT/GR/ GCE (inset: the linear relationship between the oxidation peak current and square root of the scan rate $(n=3))$.

linearity $(y=0.0298 x+1.0340)$ (Fig. S8, ESI $\dagger)$. Using the relationship between $E_{\mathrm{pa}}$ and $\ln \nu$, the number of electrons involved in the irreversible oxidation of nicotine can be determined using the following Laviron eqn (3). ${ }^{73}$

$$
E_{\mathrm{pa}}=E^{\circ}+\left(\frac{R T}{\alpha n F}\right) \ln \left(\frac{R T k^{\circ}}{\alpha n F}\right)+\left(\frac{R T}{\alpha n F}\right) \ln \nu
$$

where $\alpha$ is the co-efficient of charge transfer, $n$ is the number of electrons involved in the reaction, $R$ is the gas constant, $T$ is the temperature and $F$ is the Faraday constant. Here, the ' $\alpha n$ ' was calculated as 0.86 . Because the nicotine oxidation is an irreversible process, the charge transfer coefficient was assumed as 0.5 . Thus, ' $n$ ' was calculated as 1.72 , which revealed that during the nicotine oxidation, two electrons were involved in the electro-oxidation process on PEDOT/GR/GCE. The electrooxidation of nicotine occurred due to the hydroxylation on the n-methyl group (Scheme 2). ${ }^{74,75}$

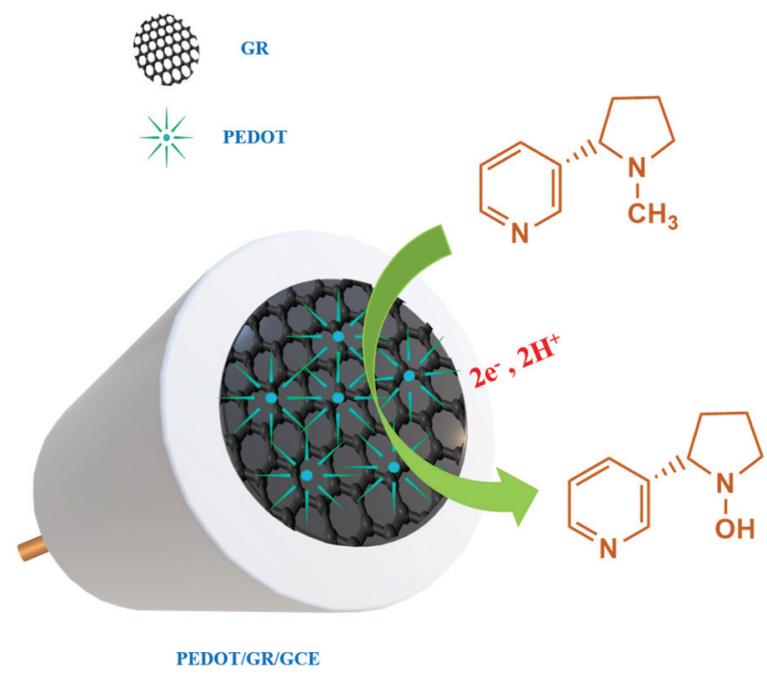

Scheme 2 Electrochemical oxidation mechanism of nicotine on PEDOT/ GR/GCE.

\subsection{Effect of $\mathrm{pH}$ on nicotine oxidation}

The electrochemical activity of PEDOT/GR/GCE was tested in different $\mathrm{pH}$ solutions. CVs were recorded in various $\mathrm{pH}$ buffer solutions (from 3 to 11) with $100 \mu \mathrm{M}$ nicotine on PEDOT/GR/ GCE. The corresponding nicotine oxidation peak potentials and peak currents were recorded at different $\mathrm{pH}$ values ( $\mathrm{pH} 3$ to 11), as shown in Fig. 8. When the $\mathrm{pH}$ was increased from 3 to 11, the nicotine oxidation potential shifted to the less positive side due to the involvement of the same number of protons and electrons. Furthermore, a non-linear graph was plotted between the $\mathrm{pH}$ and nicotine oxidation peak currents (Fig. S9, ESI $\dagger$ ). The maximum nicotine oxidation peak current was observed at $\mathrm{pH}$ 7. It should be mentioned that at $\mathrm{pH} 9$, the overpotential of nicotine decreased, and at the same time, the oxidation peak current decreased. Therefore, $\mathrm{pH} 7$ was selected as the optimum $\mathrm{pH}$ for further experiments. A linear graph was drawn from the plot of different $\mathrm{pH}$ values $v s$. the oxidation potential of nicotine as $y=0.0525 x-1.2991(x=\mathrm{pH} ; y=\mathrm{V})$ with $r^{2}$ of 0.971 (inset of Fig. 8). The scientific relationship between $\mathrm{pH}$ and $E_{\mathrm{pa}}$ can be expressed by the following Nernst eqn (4). ${ }^{76}$

$$
E_{\mathrm{pa}}=E^{0}+\frac{0.0591}{n} \log \left[\frac{(\mathrm{OX})^{a}}{(R)^{b}}\right]-\left(\frac{0.0591 m}{n}\right) \mathrm{pH}
$$

where ' $m$ ' and ' $n$ ' represent the number of protons and electrons involved in the electrochemical reaction and ' $a$ ' and ' $b$ ' are the oxidant and reductant coefficients in the reaction. In this case, the calculated slope value was $0.0525 \mathrm{~V}$, which indicated that the same number of protons and electrons were involved in the oxidation of nicotine (Scheme 2).

\subsection{Optimization of GR loading and EDOT polymerization}

The electrochemical activity of the modified electrode can be affected by the amount of GR present in the composite. To study the effect of GR concentration, GR dispersions were prepared with different concentrations (from 1 to $9 \mathrm{mg} \mathrm{mL}^{-1}$ ). From the each concentrations, $6 \mu \mathrm{L}$ of GR dispersion was taken and coated on the GCE surface for the electro-oxidation of nicotine

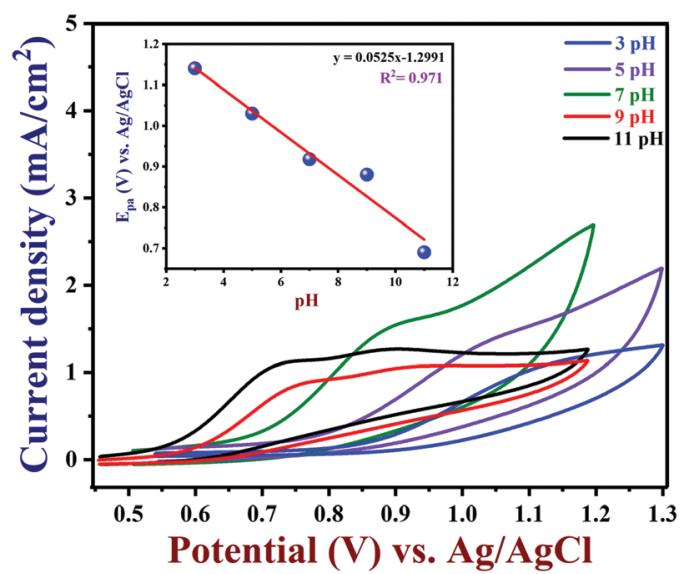

Fig. 8 Effect of $\mathrm{pH}$ on the oxidation of $100 \mu \mathrm{M}$ nicotine in $0.1 \mathrm{M}$ PBS with various $\mathrm{pH}$ (from 3 to 11) on a PEDOT/GR/GCE at a scan rate of $0.02 \mathrm{~V} \mathrm{~s}^{-1}$ (inset: a linear plot of the $E_{\mathrm{pa}}$ of nicotine oxidation vs. $\mathrm{pH}$ ). 

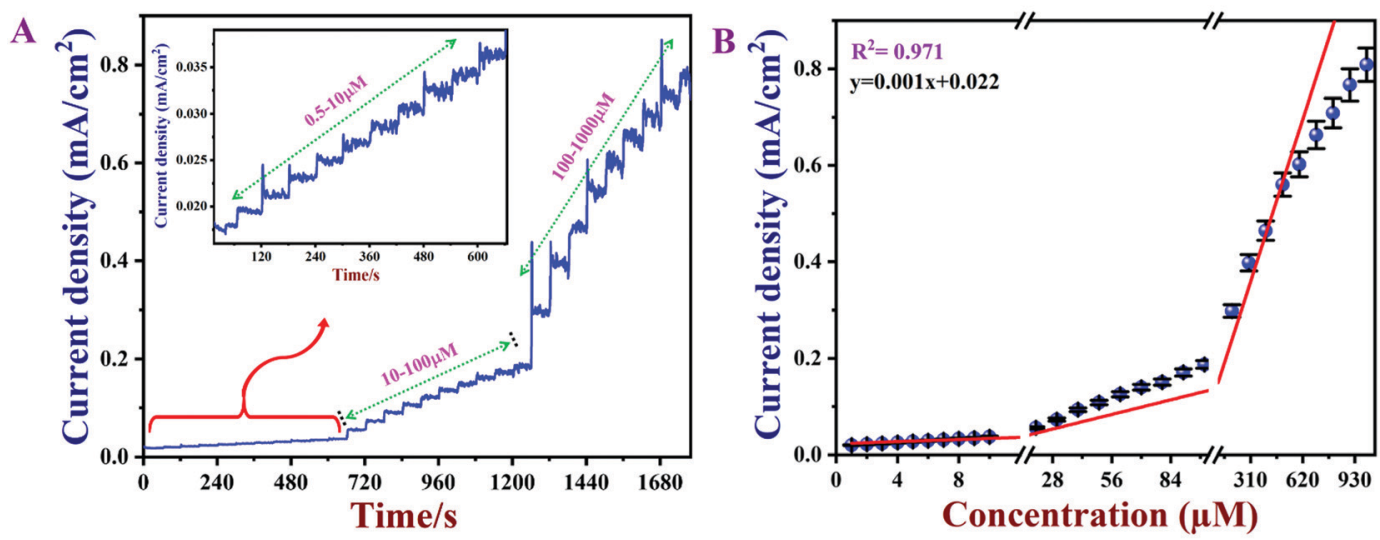

Fig. 9 (A) Amperometric response of PEDOT/GR/GCE for consecutive additions of nicotine (each $60 \mathrm{~s}$ ) from $0.5-1000 \mu \mathrm{M}$ in $0.1 \mathrm{M}$ PBS (pH 7) at an applied potential of $+0.91 \mathrm{~V}$. The electrolyte was stirred at $1000 \mathrm{rpm}$. (B) Calibration plot between the oxidation peak currents vs. the concentration of nicotine $(n=3)$.

$(100 \mu \mathrm{M})$ in $0.1 \mathrm{M}$ PBS (pH 7). A graph was plotted between the nicotine oxidation peak currents and concentration of GR present on the GCE, as shown in Fig. S10 (ESI $\dagger$ ). As can be seen, the oxidation peak currents of nicotine gradually increased with increasing GR concentration on GCE from 1 to $5 \mathrm{mg} \mathrm{mL}{ }^{-1}$, and they started to decrease (from 6 to $9 \mathrm{mg} \mathrm{mL}^{-1}$ ) after that. This may be due to saturated GR film formation on the electrode surface, which may inhibit the interaction between nicotine and the electrode. ${ }^{77,78}$ From this study, $6 \mu \mathrm{L}$ of $5 \mathrm{mg} \mathrm{mL}{ }^{-1}$ GR concentration was found to be the optimum value, and it was used to prepare the sensor for the detection of nicotine.

The PEDOT thickness on the GR/GCE surface may also influence the nicotine oxidation peak current. To determine the optimum PEDOT thickness, PEDOT polymer film was deposited on GR/GCE by varying the electro-polymerization cycles (from 3 to 20 cycles). As-prepared PEDOT/GR/GCE electrodes with varied PEDOT thicknesses were used to oxidize $100 \mu \mathrm{M}$ nicotine in $0.1 \mathrm{M}$ PBS (pH 7). A graph was plotted between the nicotine oxidation peak currents and the number of EDOT polymerization cycles (Fig. S11, ESI †). Initially, the nicotine oxidation peak currents increased with the thickness of the PEDOT films. However, after the 10th cycle, the nicotine oxidation peak current started to decrease. Hence, the PEDOT film deposited with 10 cycles was used to prepare the sensor for the detection of nicotine.

\subsection{Calibration graph and limit of detection (LOD)}

Amperometry can be used to prepare calibration graphs because it offers high sensitivity, good reproducibility and a higher limit of detection (LOD). ${ }^{4}$ Fig. 9A shows the amperograms recorded with different nicotine concentrations (each addition made after every $60 \mathrm{~s}$ ) in $0.1 \mathrm{M}$ PBS (pH 7) at an applied potential of $+0.91 \mathrm{~V}$. Moreover, the standard deviations (SD) and error bars were estimated by three replicate measurements. Fig. 9B displays the calibration graph of nicotine, which was made by an amperometry curve recorded using different concentrations of nicotine and the corresponding oxidation currents. The oxidation currents increased linearly with additions of various concentrations of nicotine from 0.5 to $1000 \mu \mathrm{M}$. The linear equation was obtained as $y=0.001 x+0.022$ with $r^{2}$ of 0.971 . The PEDOT/GR/GCE sensor response time was $\sim 2 \mathrm{~s}$ for nicotine. The LOD was calculated using the following eqn (5).

$$
\mathrm{LOD}=\frac{3 \mathrm{SD}}{S}
$$

where SD is the standard deviation of the blank $\left(1.52 \times 10^{-5}\right)$ and $\mathrm{S}$ is the slope of the calibration graph $\left(1.09 \times 10^{-3}\right)$. The calculated LOD was listed with the other reported electrochemical sensors for nicotine in Table S1 (ESI $\dagger)^{1,4,17,18,74,79-86}$ This new sensor showed a lower LOD, high selectivity and wide linear range of detection for nicotine due to the $\pi-\pi$ interaction of the PEDOT/ GR with the nicotine. ${ }^{87}$ In addition, the higher electro-active surface area of the PEDOT/GR may have provided a 3D porous network with more active sites towards favorable nicotine oxidation.

\subsection{Real sample analysis}

Next, PEDOT/GR/GCE was employed to detect nicotine levels in tobacco samples. The amperograms were recorded using a PEDOT/GR/GCE as a working electrode in $0.1 \mathrm{M} \mathrm{PBS} \mathrm{(pH} \mathrm{7)} \mathrm{with}$ subsequent additions of tobacco samples (see the Experimental section for the preparation of the tobacco samples) (Fig. 10). In addition, standard nicotine solutions ( 1 to $3 \mu \mathrm{M}$ ) were spiked into $0.1 \mathrm{M}$ PBS with tobacco samples, and the concentrations were determined by the same PEDOT/GR/GCE sensor. Finally, the nicotine concentrations in tobacco samples and the spiked nicotine concentrations were calculated by the standard addition method. ${ }^{88,89}$ The nicotine recovery values were in the range between $99.3 \%$ and $102.6 \%$ (Table 1). This indicated that our proposed PEDOT/GR/GCE-based sensor may be a valuable transducer for the accurate detection of nicotine content in tobacco samples.

3.9.1 Reproducibility, stability and selectivity. The reproducibility of the PEDOT/GR/GCE was also examined. It was found that the as-prepared PEDOT/GR-modified GCE could be reused after rinsing with PBS. Five individually prepared PEDOT/GR/GCE samples were tested against nicotine oxidation $(50 \mu \mathrm{M})$ and showed average current responses of $96.6 \%$ with a 


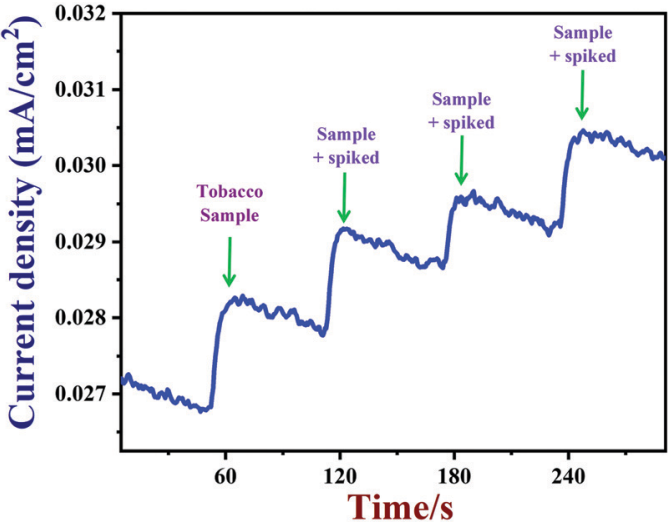

Fig. 10 Amperometric response of PEDOT/GR/GCE in 0.1 M PBS with successive addition of tobacco samples (real samples) containing different concentrations of nicotine at an applied potential of $+0.91 \mathrm{~V}$. The solution was stirred at a rate of $1000 \mathrm{rpm}$.

Table 1 Detection of nicotine in tobacco samples before and after spiking of nicotine using PEDOT/GR/GCE as a transducer

\begin{tabular}{|c|c|c|c|c|c|}
\hline $\begin{array}{l}\text { S. } \\
\text { no. }\end{array}$ & Sample & $\begin{array}{l}\text { Added } \\
(\mu \mathrm{M})\end{array}$ & Found $(\mu \mathrm{M})$ & $\mathrm{RSD}^{a}{ }^{a}$ & $\begin{array}{l}\text { Recovery } \\
\%\end{array}$ \\
\hline 1 & Tobacco sample & - & $4.90 \pm 0.005$ & 2.45 & - \\
\hline 2 & Tobacco sample + spiked & 1 & $5.99 \pm 0.004$ & 2.23 & 101.6 \\
\hline 3 & Tobacco sample + spiked & 2 & $6.85 \pm 0.001$ & 1.00 & 99.3 \\
\hline 4 & Tobacco sample + spiked & 3 & $8.13 \pm 0.003$ & 2.77 & 102.6 \\
\hline
\end{tabular}

relative standard deviation, RSD, of $2.7 \%$ (Fig. S12, ESI $\dagger$ ). Next, the reusability of the PEDOT/GR-modified electrode was carried out by detecting nicotine $(100 \mu \mathrm{M})$ at given regular time intervals in 0.1 M PBS (pH 7) (Fig. 11A). After each measurement, the PEDOT/GR/GCE was stored at $4{ }^{\circ} \mathrm{C}$. After storage for 30 days, the PEDOT/GR/GCE sensor retained about $77 \%$ of its electro-activity, which suggested that the proposed sensor was highly stable and could be used for repeated detection of nicotine.
To ascertain the selectivity of the sensor, amperograms were recorded in $0.1 \mathrm{M}$ PBS (pH 7) with $5 \mu \mathrm{M}$ nicotine and subsequent additions of common interfering molecules, such as anhydrous dextrose (GL), ascorbic acid (AA), uric acid (UA), melamine (MA), hydrogen peroxide (HP) and dopamine (DA) (the concentration of each compound was $30 \mu \mathrm{M})$. These molecules were selected for the selectivity study because of their widespread availability in human body fluids and environmental samples. ${ }^{18,90}$ Furthermore, the interferences due to other alkaloids that exist in tobacco were not tested because of their lower content $(0.2-0.5 \%)$, which may not affect the oxidation of nicotine. ${ }^{18,85,91,92}$ As shown in Fig. 11B, the nicotine oxidation peak current was stable even after the addition of the interfering biomolecules. This result indicated that these molecules did not produce any current signals and that the PEDOT/GR composite showed high selectivity for nicotine over these molecules. The above studies indicated that PEDOT/GR/GCE can be used to detect nicotine with high selectivity.

\section{Conclusion}

In summary, GR was prepared by a simple electrochemical exfoliation method using graphite sheets. The as-prepared GR was characterized by HR-TEM to confirm its layered structure. Furthermore, PEDOT was electro-deposited on a GR/GCE surface, and the PEDOT/GR hybrid film formation was confirmed by Raman spectroscopy. In addition, the surface morphology of the hybrid film was investigated by FE-SEM. The as-prepared PEDOT/ GR/GCE showed enhanced electrochemical activity and excellent electro-catalytic activity for nicotine oxidation. PEDOT/GR/GCE linearly responded to nicotine from $0.5-1000 \mu \mathrm{M}$, and the LOD was found to be $47 \mathrm{nM}$. In addition, the PEDOT/GR-based sensor showed several advantages, such as high reproducibility, high selectivity, rapid response, and high stability, when used for the detection of nicotine. Finally, PEDOT/GR/GCE was successfully used to detect nicotine concentrations in tobacco samples with high recoveries. We believe that our proposed PEDOT/GR/GCE sensor can be used to detect nicotine with accuracy in real-world samples.
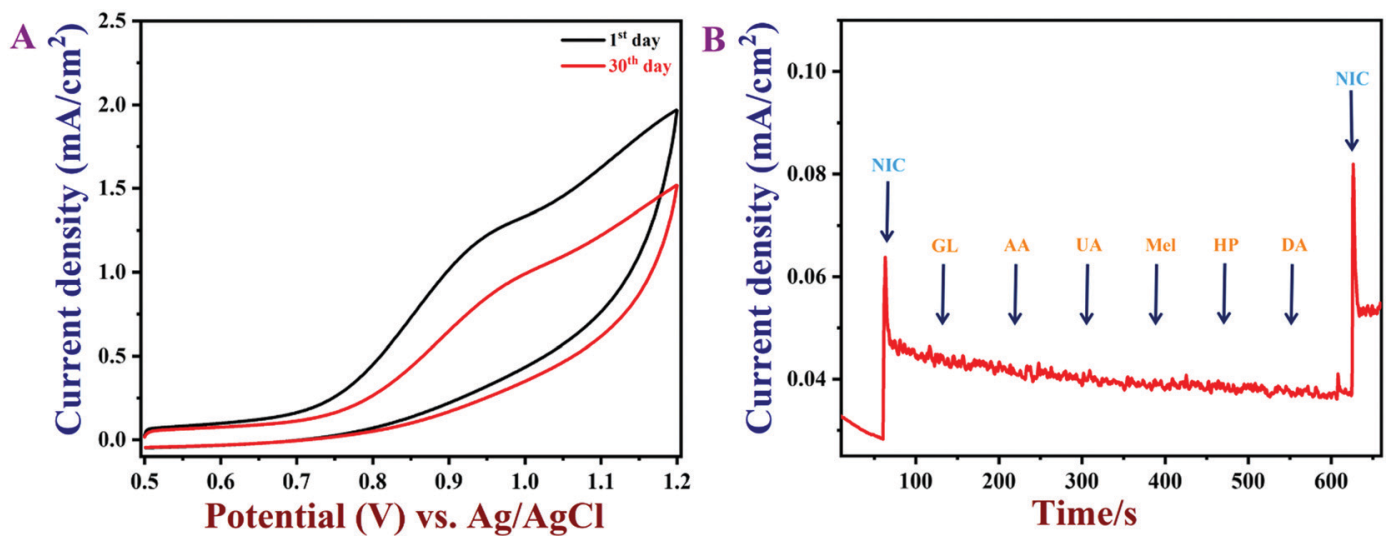

Fig. 11 (A) CVs of PEDOT/GR/GCE in $0.1 \mathrm{M}$ PBS (pH 7) containing $100 \mu \mathrm{M}$ nicotine with different storage times. (B) The amperometric response of $\mathrm{PEDOT} / \mathrm{GR} / \mathrm{GCE}$ with the additions of various interfering molecules (GL, AA, UA, Mel, HP, DA; concentration of each compound was $30 \mu \mathrm{M}$ ) with $5 \mu \mathrm{M}$ of nicotine at an applied potential of $+0.91 \mathrm{~V}$. The PBS was stirred at $1000 \mathrm{rpm}$. 


\section{Conflicts of interest}

There are no conflicts to declare.

\section{Acknowledgements}

We thank Department of Science \& Technology (International Bilateral Cooperation Division) for financial support through the "INDO-RUSSIA Project (File No.: INT/RUS/RFBR/385)". J. R thanks SRM-IST for the PhD student fellowship. We acknowledge the HRTEM FACILITY at SRMIST which was supported by the project from MNRE (Project No. 31/03/2014-15/PVSE-R\&D), Government of India. We also acknowledge the SRM Institute of Science and Technology for providing "micro-Raman facility".

\section{References}

1 A. Levent, Y. Yardim and Z. Senturk, Electrochim. Acta, 2009, 55, 190-195.

2 B. Lin, J. Chen, Y. Zeng, L. Li, B. Qiu, Z. Lin and L. Guo, ACS Sens., 2019, 4, 1844-1850.

3 A. L. A. M. Stolker, W. Niesing, E. A. Hogendoorn, A. Bisoen Rambali and W. Vleeming, J. Chromatogr. A, 2003, 1020, 35-43.

4 R. Jerome and A. K. Sundramoorthy, Anal. Chim. Acta, 2020, 1132, 110-120.

5 R. L. Siegel, K. D. Miller and A. Jemal, Ca-Cancer J. Clin., 2016, 66, 7-30.

6 P. A. Newhouse, A. Potter, M. Kelton and J. Corwin, Biol. Psychiatry, 2001, 49, 268-278.

7 G. K. Lloyd and M. Williams, J. Pharmacol. Exp. Ther., 2000, 292, 461-467.

8 J. I. Seeman, J. A. Fournier, J. B. Paine and B. E. Waymack, J. Agric. Food Chem., 1999, 47, 5133-5145.

9 F. Moriya, Y. Hashimoto and J. Furumiya, Forensic Sci. Int., 2007, 168, 102-105.

10 D.-S. Tang, L. Zhang, H.-L. Chen, Y.-R. Liang, J.-L. Lu, H.-L. Liang and X.-Q. Zheng, Sep. Purif. Technol., 2007, 56, 291-295.

11 M. C. Acosta, A. R. Buchhalter, A. B. Breland, D. C. P. Hamilton and T. Eissenberg, Nicotine Tob. Res., 2004, 6, 615-620.

12 M. Page-Sharp, T. W. Hale, L. P. Hackett, J. H. Kristensen and K. F. Ilett, J. Chromatogr. B: Anal. Technol. Biomed. Life Sci., 2003, 796, 173-180.

13 A. W. Abu-Qare and M. B. Abou-Donia, J. Chromatogr. B: Biomed. Sci. Appl., 2001, 757, 295-300.

14 J. J. Langone, H. B. Gjika and H. Van Vunakis, Biochemistry, 1973, 12, 5025-5030.

15 M. S. Lin, J. S. Wang and C. H. Lai, Electrochim. Acta, 2008, 53, 7775-7780.

16 A. M. Hossain and S. M. Salehuddin, Arabian J. Chem., 2013, 6, 275-278.

17 M. Stočes and I. Švancara, Electroanalysis, 2014, 26, 2655-2663.

18 H. Kassa, A. Geto and S. Admassie, Bull. Chem. Soc. Ethiop., 2013, 27, 321-328.

19 M. R. Miah, J. Masud and T. Ohsaka, Electrochim. Acta, 2008, 54, 316-321.
20 T. F. Manny, R. Miah, F. Islam, D. Sen and R. Mahmud, Russ. J. Electrochem., 2020, 56, 570-577.

21 M. R. Miah, M. T. Alam and T. Ohsaka, Anal. Chim. Acta, 2010, 669, 75-80.

22 D. A. Dikin, S. Stankovich, E. J. Zimney, R. D. Piner, G. H. B. Dommett, G. Evmenenko, S. T. Nguyen and R. S. Ruoff, Nature, 2007, 448, 457-460.

23 A. K. Sundramoorthy, T. H. Vignesh Kumar and S. Gunasekaran, in Graphene Bioelectronics, Advanced Nanomaterials, ed. A. B. T.-G. B. Tiwari, Elsevier, 2018, pp. 267-306.

24 A. K. Sundramoorthy and S. Gunasekaran, TrAC, Trends Anal. Chem., 2014, 60, 36-53.

25 R. D. Nagarajan and A. K. Sundramoorthy, Sens. Actuators, B, 2019, 301, 127132.

26 N. Murugan, A. Sundaramurthy, S.-M. Chen and A. K. Sundramoorthy, Mater. Res. Express, 2017, 4, 124005.

27 H. He, J. Klinowski, M. Forster and A. Lerf, Chem. Phys. Lett., 1998, 287, 53-56.

28 K. Nakada, M. Fujita, G. Dresselhaus and M. S. Dresselhaus, Phys. Rev. B: Condens. Matter Mater. Phys., 1996, 54, 17954.

29 S. Stankovich, R. D. Piner, X. Chen, N. Wu, S. T. Nguyen and R. S. Ruoff, J. Mater. Chem., 2006, 16, 155-158.

30 T. H. V. Kumar, S. K. Yadav and A. K. Sundramoorthy, J. Electrochem. Soc., 2018, 165, B848-B861.

31 Y. Hernandez, V. Nicolosi, M. Lotya, F. M. Blighe, Z. Sun, S. De, I. T. McGovern, B. Holland, M. Byrne, Y. K. Gun'Ko, J. J. Boland, P. Niraj, G. Duesberg, S. Krishnamurthy, R. Goodhue, J. Hutchison, V. Scardaci, A. C. Ferrari and J. N. Coleman, Nat. Nanotechnol., 2008, 3, 563-568.

32 K. R. Paton, E. Varrla, C. Backes, R. J. Smith, U. Khan, A. O'Neill, C. Boland, M. Lotya, O. M. Istrate, P. King, T. Higgins, S. Barwich, P. May, P. Puczkarski, I. Ahmed, M. Moebius, H. Pettersson, E. Long, J. Coelho, S. E. O’Brien, E. K. McGuire, B. M. Sanchez, G. S. Duesberg, N. McEvoy, T. J. Pennycook, C. Downing, A. Crossley, V. Nicolosi and J. N. Coleman, Nat. Mater., 2014, 13, 624.

33 R. Sakamoto, K. Hoshiko, Q. Liu, T. Yagi, T. Nagayama, S. Kusaka, M. Tsuchiya, Y. Kitagawa, W.-Y. Wong and H. Nishihara, Nat. Commun., 2015, 6, 6713.

34 Y. Wang, L. Li, L. Yan, X. Gu, P. Dai, D. Liu, J. G. Bell, G. Zhao, X. Zhao and K. M. Thomas, Chem. Mater., 2018, 30, 3048-3059.

35 J. Rajendran, A. N. Reshetilov and A. K. Sundramoorthy, RSC Adv., 2021, 11, 3445-3451.

36 A. K. Sundramoorthy, Y. Wang, J. Wang, J. Che, Y. X. Thong, A. C. W. Lu and M. B. Chan-Park, Sci. Rep., 2015, 5, 1-13.

37 N. G. Yasri, A. K. Sundramoorthy, W.-J. Chang and S. Gunasekaran, Front. Mater., 2014, 1, 33.

38 P. Garrigue, M.-H. Delville, C. Labrugère, E. Cloutet, P. J. Kulesza, J. P. Morand and A. Kuhn, Chem. Mater., 2004, 16, 2984-2986.

39 H. Ba, L. Truong-Phuoc, C. Pham-Huu, W. Luo, W. Baaziz, T. Romero and I. Janowska, ACS Omega, 2017, 2, 8610-8617.

40 F. Parnianchi, M. Nazari, J. Maleki and M. Mohebi, Int. Nano Lett., 2018, 8, 229-239.

41 X. Luo, C. L. Weaver, S. Tan and X. T. Cui, J. Mater. Chem. B, 2013, 1, 1340-1348. 
42 S. Nambiar and J. T. W. Yeow, Biosens. Bioelectron., 2011, 26, 1825-1832.

43 J. Heinze, B. A. Frontana-Uribe and S. Ludwigs, Chem. Rev., 2010, 110, 4724-4771.

44 W. Si, W. Lei, Z. Han, Y. Zhang, Q. Hao and M. Xia, Sens. Actuators, B, 2014, 193, 823-829.

45 F. Jiang, R. Yue, Y. Du, J. Xu and P. Yang, Biosens. Bioelectron., 2013, 44, 127-131.

46 E. Spain, T. E. Keyes and R. J. Forster, Biosens. Bioelectron., 2013, 41, 65-70.

47 C. Zhu, J. Zhai, D. Wen and S. Dong, J. Mater. Chem., 2012, 22, 6300-6306.

48 S. Ameen, M. S. Akhtar and H. S. Shin, Sens. Actuators, B, 2012, 173, 177-183.

49 A. K. Sundramoorthy, B. S. Premkumar and S. Gunasekaran, ACS Sens., 2016, 1, 151-157.

50 O. Sadak, W. Wang, J. Guan, A. K. Sundramoorthy and S. Gunasekaran, ACS Appl. Nano Mater., 2019, 2, 4386-4394.

51 O. Sadak, A. K. Sundramoorthy and S. Gunasekaran, Carbon, 2018, 138, 108-117.

52 Y. Zhu, M. T. Otley, A. Kumar, M. Li, X. Zhang, C. Asemota and G. A. Sotzing, Chem. Commun., 2014, 50, 8167-8170.

53 J.-H. Kang, S.-M. Paek, Y. Bin Choy, S.-J. Hwang and J.-H. Choy, J. Nanosci. Nanotechnol., 2007, 7, 4131-4134.

54 Y. Jing, X. Yuan, Q. Yuan, K. He, Y. Liu, P. Lu, H. Li, B. Li, H. Zhan and G. Li, Sci. Rep., 2016, 6, 29230.

55 A. I. Melato, M. H. Mendonça and L. M. Abrantes, J. Solid State Electrochem., 2009, 13, 417-426.

56 J. Heinze, A. Rasche, M. Pagels and B. Geschke, J. Phys. Chem. B, 2007, 111, 989-997.

57 S. Berchmans, Sci. Rep., 2019, 9, 19184.

58 S. C. Yan, Z. S. Li and Z. G. Zou, Langmuir, 2009, 25, 10397-10401.

59 M. Wang, T. Zhang, D. Mao, Y. Yao, X. Zeng, L. Ren, Q. Cai, S. Mateti, L. H. Li, X. Zeng, G. Du, R. Sun, Y. Chen, J.-B. Xu and C.-P. Wong, ACS Nano, 2019, 13, 7402-7409.

60 G. Jiang, Z. Lin, C. Chen, L. Zhu, Q. Chang, N. Wang, W. Wei and H. Tang, Carbon, 2011, 49, 2693-2701.

61 M. S. Cho, Y. Y. Yun, J. D. Nam, Y. Son and Y. Lee, Synth. Met., 2008, 158, 1043-1046.

62 F. Tran-Van, S. Garreau, G. Louarn, G. Froyer and C. Chevrot, J. Mater. Chem., 2001, 11, 1378-1382.

63 S. Garreau, G. Louarn, J. P. Buisson, G. Froyer and S. Lefrant, Macromolecules, 1999, 32, 6807-6812.

64 S. Aeiyach, J. J. Aaron, M. Jouini, K. I. Chane-Ching, J. C. Lacroix, J. Tanguy and P. C. Lacaze, ThinPolyheteroaromatic Films Synthesized in Organized Media: Structures and Properties, ACS Symposium Series, ACS Publications, 2003, 38-51.

65 S. Dhillon and R. Kant, J. Chem. Sci., 2017, 129, 1277-1292.

66 M. C. Granger and G. M. Swain, J. Electrochem. Soc., 1999, 146, 4551.

67 A. J. Bard and L. R. Faulkner, Fundamentals and applications, Wiley New York, 2001, vol. 2.
68 E. Barsoukov and J. R. Macdonald, Impedance spectroscopy: theory, experiment, and applications, John Wiley \& Sons, New York, 2005.

69 E. N. Primo, P. Cañete-Rosales, S. Bollo, M. D. Rubianes and G. A. Rivas, Colloids Surf., B, 2013, 108, 329-336.

70 N. Murugan, R. Jerome, M. Preethika, A. Sundaramurthy and A. K. Sundramoorthy, J. Mater. Sci. Technol., 2020, 72, 122-131.

71 E. J. Ukpong, I. A. Udoetok and N. W. Akpanudo, J. Appl. Chem., 2013, 5, 50-55.

72 M. Opitz, J. Yue, J. Wallauer, B. Smarsly and B. Roling, Electrochim. Acta, 2015, 168, 125-132.

73 E. Laviron, J. Electroanal. Chem. Interfacial Electrochem., 1974, 52, 355-393.

74 X. Li, H. Zhao, L. Shi, X. Zhu, M. Lan, Q. Zhang and Z. H. Fan, J. Electroanal. Chem., 2017, 784, 77-84.

75 T. W. B. Lo, L. Aldous and R. G. Compton, Sens. Actuators, B, 2012, 162, 361-368.

76 V. Erady, R. J. Mascarenhas, A. K. Satpati, S. Detriche, Z. Mekhalif, J. Delhalle and A. Dhason, Mater. Sci. Eng., C, 2017, 76, 114-122.

77 A. Uzunoglu, A. S. Ahsen, F. Dundar, A. Ata and O. Ozturk, J. Appl. Electrochem., 2017, 47, 139-155.

78 Y. Tabe, M. Nishino, H. Takamatsu and T. Chikahisa, J. Electrochem. Soc., 2011, 158, B1246.

79 A. Karthika, P. Karuppasamy, S. Selvarajan, A. Suganthi and M. Rajarajan, Ultrason. Sonochem., 2019, 55, 196-206.

80 Y. Jing, B. Yu, P. Li, B. Xiong, Y. Cheng, Y. Li, C. Li, X. Xiao, M. Chen and L. Chen, Sci. Rep., 2017, 7, 14332.

81 L. Highton, R. O. Kadara, N. Jenkinson, B. Logan Riehl and C. E. Banks, Electroanalysis, 2009, 21, 2387-2389.

82 M. J. Sims, N. V. Rees, E. J. F. Dickinson and R. G. Compton, Sens. Actuators, B, 2010, 144, 153-158.

83 C.-T. Wu, P.-Y. Chen, J.-G. Chen, V. Suryanarayanan and K.-C. Ho, Anal. Chim. Acta, 2009, 633, 119-126.

84 S.-J. Wang, H.-W. Liaw and Y.-C. Tsai, Electrochem. Commun., 2009, 11, 733-735.

85 Ľ. Švorc, D. M. Stanković and K. Kalcher, Diamond Relat. Mater., 2014, 42, 1-7.

86 A. Geto, M. Amare, M. Tessema and S. Admassie, Electroanalysis, 2012, 24, 659-665.

87 Y. Xu, W. Lei, J. Su, J. Hu, X. Yu, T. Zhou, Y. Yang, D. Mandler and Q. Hao, Electrochim. Acta, 2018, 259, 994-1003.

88 K. Cinková, L. Dianová, M. Vojs, M. Marton and Ľ. Švorc, Acta Chim. Slovaca, 2015, 8, 166-171.

89 K. Liu, W.-Z. Wei, J.-X. Zeng, X.-Y. Liu and Y.-P. Gao, Anal. Bioanal. Chem., 2006, 385, 724-729.

90 E. Mehmeti, T. Kilic, C. Laur and S. Carrara, Microchem. J., 2020, 158, 105155.

91 J. M. Garrigues, A. Pérez-Ponce, S. Garrigues and M. de la Guardia, Anal. Chim. Acta, 1998, 373, 63-71.

92 H. Xiong, Y. Zhao, P. Liu, X. Zhang and S. Wang, Microchim. Acta, 2010, 168, 31-36. 